\title{
Een hersentumor: lokale beschadiging of ziek netwerk?
}

LINDA DOUW

DeH ongaarse schrijver Frigyes Karinthy steldein zijn korteverhaal Ketenen uit 1929 dat allemensen in de wereld met elkaar verbonden zijn via maximaal vijf anderepersonen. $\mathrm{H}$ oewel Karinthy geen bewijs had voor dezeaanname, bleek hij het wél bij het juiste eind tehebben. Debekendepsycholoog Stanley M ilgram bevestigde namelijk in dejaren 60 met een ingenieus brievenexperiment het vermoeden van Karinthy. M ilgram stuurde 160 brieven naar willekeurig gekozen personen in de VerenigdeStaten, waarin slechts één opdracht stond: zorg ervoor dat deze brief terechtkomt bij persoon $X$ in Boston door hem door testuren naar iemand dieje bij voornaam kent en diemisschien persoon X kent ( M ilgram, 1967). H et lijkt onwaarschijnlijk dat debrieven $X$ zouden bereiken, maar bijna een derdevan de brieven vond zijn wegnaar Boston! Nog interessanter: de brieven kwamen gemiddeld na slechts vijf 'tussenstations' aan. Zo werden niet alleen de six degrees of separation voor het eerst wetenschappelijk aangetoond, maar werd ook voor het eerst een brug geslagen tussen de voorheen vrij wiskundigetak van denetwerkstudieen desocialepsychologie. $\mathrm{H}$ et is medehierdoor dat detoepassing van netwerktheorieop en heleboel verschillende typen netwerken in zwang is geraakt.

Wat voegt dezenetwerktheorienu toe aan het hersenonderzoek? Al eeuwenlang proberen wete begrijpen hoeons brein in elkaar zit, maar degeboekte resultaten zijn vooralsnog onbevredigend. Er wordt vaak geprobeerd om specifiekefuncties toeteschrijven

M w. dr. L. Douw, neuropsychologe, postdoc onderzoeker, Afdeling neurologie VUmc, L.douw@vumc.nl. aan bepaaldehersengebieden, maar het lokaliseren van functies is eigenlijk alleen goed mogelijk voor vij basalefuncties, zoals beweging. Het is moeilijk om taal te plaatsen in een specifiek hersengebied, en het is nog steeds onmogelijk om eigenschappen als perfectionisme of extraversiete lokaliseren. Blijven wenu proberen om iederefunctietereduceren toteen bepaald stukjehersenen, of wordt het tijd om een nieuw gezichtspunt te proberen? Het wordt steeds duidelijker dat denetwerktheorieniet alleen vanuit wiskundig of sociaal psychologisch oogpunt interessant is, ook de hersenen vormen een netwerk. Sterker nog, dehersenen zijn waarschijnlijk het meest geavanceerdenetwerk dater bestaat.

In ons hersenweb zijn tweezeer belangrijkeeigenschappen van optimaal functionerendenetwerken verenigd. Ten eerstegel dt het principe van desix degrees of separation ook in dehersenen: ieder hersengebiedje is via een klein aantal stappen verbonden met alleanderehersengebieden. Ten tweedevindt er clustering plaats: in socialenetwerken zijn bijvoorbeeld vrienden van een bepaald persoon vaak ook met elkaar bevriend, wat ervoor zorgt dat kliekjes ontstaan. In dehersenen zorgt localeclustering ervoor dat wat meer specifiekefuncties uitgevoerd kunnen worden door een bepaal d cluster. Dus, de hersenen zorgen voor lokal especial isatie door clustering, terwijl ook deglobaleintegratiegewaarborgd blijft. Dit typenetwerk wordt een small-world-netwerk genoemd. Het is gebleken dat naast dehersenen velesystemen zón smallworld-netwerk zijn, bijvoorbeeld het I nternet, het wegennet van Nederland en onzegenetischestructuur (Watts \& Strogatz, 1998).

I ronisch genoeg is Karinthy- naast zijn pioniersvisieop socialenetwerken - ook nog op een anderemanier relevant voor dit artikel: hij werd op 
46-jarige leeftijd gediagnosticeerd met een hersentumor. Detumor werd verwijderd, waarnaKarinthyeen boek schreef over zijn ervaringen met deziekteen debehandeling ervan. $\mathrm{Hij}$ was vooral bekend vanwegezijn absurdistischehumor, en schreef: 'Ilk ging van humorist naar tumorist...'. Karinthy overleed op 51-jarige leeftijd aan de gevolgen van zijn hersentumor, zoals bijna allehersentumorpatiënten.

\section{Hersentumoren \\ Primairehersentumoren (dat wil zeg- gen geen metastases of uitzaaiingen in de hersenen) maken ongeveer twee procent uit van detotaleincidentie van allesoorten kanker, wat betekent dater ongeveer 2000 nieuwe gevallen zijn in Nederland. Demeest voorko- mendesoort primairehersentumor is een glioom, dat uitgaat van degliale ofwel steunendecellen in dehersenen (ziefiguur 1). Glioompatiënten overlij- den eigenlijk allemaal aan hun ziekte; de prognosevan hersentumorpatiën- ten is dan ook substantieel slechter dan dievan patiënten met de meeste anderevormen van kanker. Demedi- aneoverleving na diagnose varieert wel: bij een laaggradig glioom (dit is}

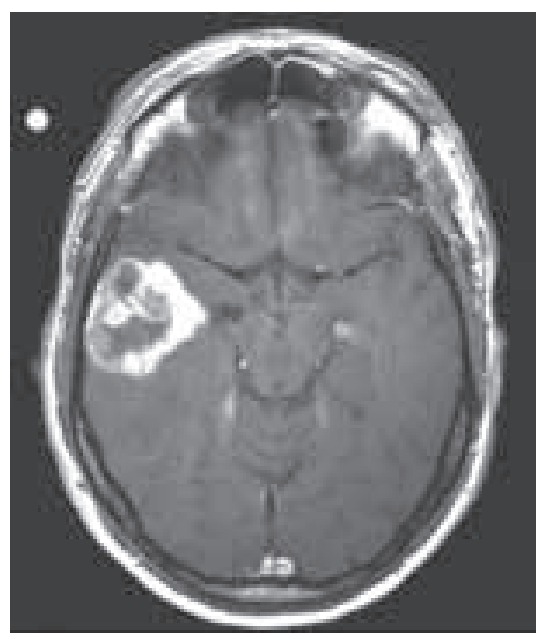

Figuur 1 MRI van een glioblastoma multiforme in de linker temporaalkwab meestal graad II ) hebben de meeste patiënten nog ongeveer acht jaar te leven. Devolgendegroep patiënten, meteen graad III hooggradig glioom, heeft al een korterelevensduur, met een overleving van gemiddeld drie jaar. Echter, patiënten met demeest agressieve vorm (een graad IV glioblastoma multiforme) overlijden meestal al na 14 maanden, ondanks uitgebrei de behandeling met operatie, chemotherapieen radi otherapie. In detijd diehun nog rest, hebben glioompatiënten vaak temaken met belastende symptomen. Bij de patiënten met laaggradig glioom is epilepsie het meest voorkomendeziekteverschijnsel, naast het feit dat detumor vaak ontdekt wordt door een epileptischeaanval. Ook bij de patiënten met hooggradig glioom komt epilepsie voor, maar in een kleiner percentage ongeveer $50 \%$ ). Het is nog onduidelijk waardoor deze epilepsie precies veroorzaakt wordt. Hetlijkt erop al sof detumor bepaal de veranderingen in deomliggendehersencellen veroorzaakt, waardoor er eerder afwijkende activiteit in dit peritumoralegebied optreedt. Het blijft echter onduidelijk waarom dezeneiging bij sommige patiënten wel leidt tot epilepsieen bij anderen niet. Bovendien kan de verspreiding van een epileptischeaanval zelfs binnen één patiënt per keer verschillen.

Ook hebben glioompatiënten dikwijls last van cognitieveachteruitgang. Jezou misschien verwachten dateen hersentumor, diezich toch op één circumscripte locatiebevindt, heel specifieke problemen zou veroorzaken. Dit ideegaat op voor basal efuncties: een tumor in delinker precentralegyrus kan bijvoorbeel d demotoriek van het rechterbeen verstoren. Bij de hogere cognitieve functies ligt het echter wat ingewikkelder. Glioompa tiënten lijken juist achteruit tegaan in hun al gemeneneuropsychologische prestaties, waardoor het hed moeilijk is om op basis van hun cognitieve problemen tevoorspellen waar detumor zich bevindt. Zehebben bijvoorbeeld moeitezich teconcentreren en hebben minder overzicht in complexe situaties (Klein et al., 2001; Taphoorn \& Klein. 2004).

Dezetweesymptomen van glioompatiënten kunnen vooral snog niet worden verklaard met behulp van traditionelelokaliserendetheorieën. Devragen diedan ook meteen netwerkperspectief worden bekeken in dit artikel zijn:

- Waarom veroorzaakt een zeer focale hersenlaesiezo'n algemene achteruitgang in het cognitief functioneren?

- Waarom hebben hersentumorpatienten vaak last van epilepsie?

- En hoekomt het dat de patiënten met laaggradi ge gliomen veel vaker last hebben van epileptischeaanvalIen dan de patiënten met sneller groeiendegliomen?

\section{De basis van het hersenweb}

Om denetwerktheorietekunnen toepassen op de hersenen moeten we eerst wat meer weten over hoe netwerken in elkaar zitten. In N europraxis I, 2011: 3-15is door Martijn van den Heuvel al uitgebreid beschreven hoe hersennetwerken in elkaar steken in zijn mooieartikel 'Het verbonden brein'. Hier volgt nog een korteopfriscursus.

l eder netwerk begint met punten en lijnen. Van socialenetwerken weten we dat tweemensen verbonden zijn doordat ze vrienden zijn, maar de verbondenheid of connectiviteit in de hersenen is nietzo eenduidig vast te stellen als in een sociaal netwerk. Voor deanatomische connectiviteit wordt bijvoorbeeld diffusion tensor imaging magnetic resonanceimaging (DTI-MRI) gebruikt, waarmee de wittestofbanen 
in dehersenen kunnen worden afgebeeld. Van belang is echter niet alleen deanatomische connectiviteit in de hersenen. Hetis minstens zo belangrijk om te weten of er daadwerkelijk communicatie plaatsvindt tussen de verschillendehersengebieden. Dit kunnen wevaststellen door middel van functioneleMRI (fMRI), elektroencefalografie (EEG) of magnetoencefalografie (MEG). Bij dezemetingen wordt in plaats van deanatomie juist de activiteit van de hersenen gemeten, waardoor een inschatting van defunctioneleconnectiviteit en dus daadwerkelijkecommunicatie kan worden gemaakt. Dezefunctionele connectiviteit is niets meer dan de correlatietussen ieder paar sensoren.

Na het berekenen van de matevan connectiviteit tussen allevoxels of sensoren kan er een netwerk gevormd worden. I ederesensor of voxel is een punt in het netwerk, terwijl de matevan connectiviteit bepaal of er een verbinding is tussen ieder paar punten, en hoesterk dezeis. Op ditmoment kunnen weeen visuele representatievan het netwerk maken, zoals in figuur 2 . In dezefiguur is een small-world-netwerk afgebeeld, waarin dehoge verbondenheid tussen buren van ieder punt, dus clustering, evident is. Declusteringcoëfficiënt meet de matevan clustering van het netwerk en kan worden uitgerekend door het aantal daadwerkelijkeverbindingen tussen buren van een punt tedelen door het totaleaantal mogelijkeverbindingen. In figuur 2 zijn verder een aantal langeafstandsverbindingen te zien, waardoor het vrij gemakkelijk is om het netwerk snel tedoorkruisen. Het concept van desix degrees of separation wordt in denetwerktheoriegemeten met de padlengte; deze wordt uitgerekend door het kortste aantal stappen tussen iedere willekeurig paar punten te bepalen en temid-

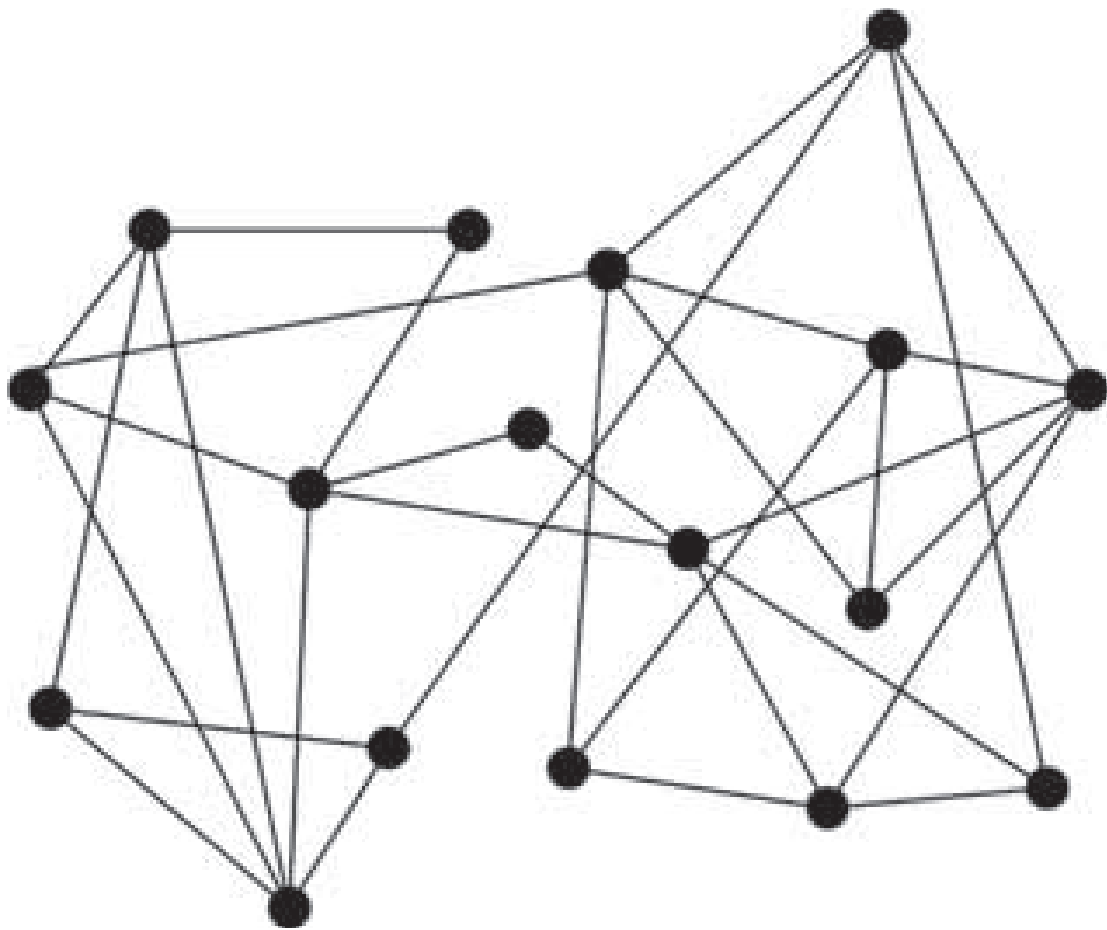

Figuur 2 Een small-world-netwerk, waarbij lokale clustering gecombineerd wordt met een korte gemiddelde padlengte.

delen over het gehelenetwerk. Een lange padlengte geeft dus aan dat het kortstepad tussen twee punten rela tief veel stappen bevat. Zo'n netwerk is hoogstwaarschijnlijk minder efficiënt wat betreft deinformatieverwerking.

\section{Lokale beschadiging en de rest van de} hersenen

Deinvloed van verschillendetypen hersenbeschadigingen op het hersenweb zijn de afgelopen jaren met behulp van denetwerktheorieonderzocht. Zo blijkt dat bijvoorbeel d een herseninfarct deanatomischeen functioneleconnectiviteit (gemeten met DTI-MRI en FMRI resp.) in het gebied van de bl oeding of ischemie sterk verstoord raken en afnemen (Wang et al., 2010; Crofts et al., 2011). Dezegebieden lijken in de maanden totjaren na een herseninfarct steeds minder een small-world-netwerk te worden. De padlengteneemt lokaal toe, terwijl declusteringcoëfficiënt juist afneemt. Interessanter is nog dat ook defunctioneleconnectiviteit in derest van dehersenen verandert. Op plekken dieverder weg liggen van het infarct neemt defunctioneleen anatomische connectiviteit echter juist toe in plaats van teverminderen (Crofts et al., 2011). Of dezetoenameeen compensatiemechanisme of juist een pathologischereactieop het infarct weerspiegelt, is nog onduidelijk.

Hoezit dat bij hersentumoren? Met behulp van MEG is gebleken dat defunctioneleconnectiviteit in het gebied van de beschadiging, dat wil zeggen detumor, sterk afneemt (Guggisberg etal., 2008). Dit terwijl in het helehersennetwerk, net zoals naeen herseninfarct, defunctioneleconnectiviteit juist toeneemt wanneer alle hersengolven worden bekeken (Bartolomei etal., 2006b; Bosma et al., 2008). Bij EEG en MEG kunnen echter ook verschillende groepen hersengolven worden onderscheden op basis van hun frequentie. lemand dierustig zit met zijn ogen dicht, heeft vooral 

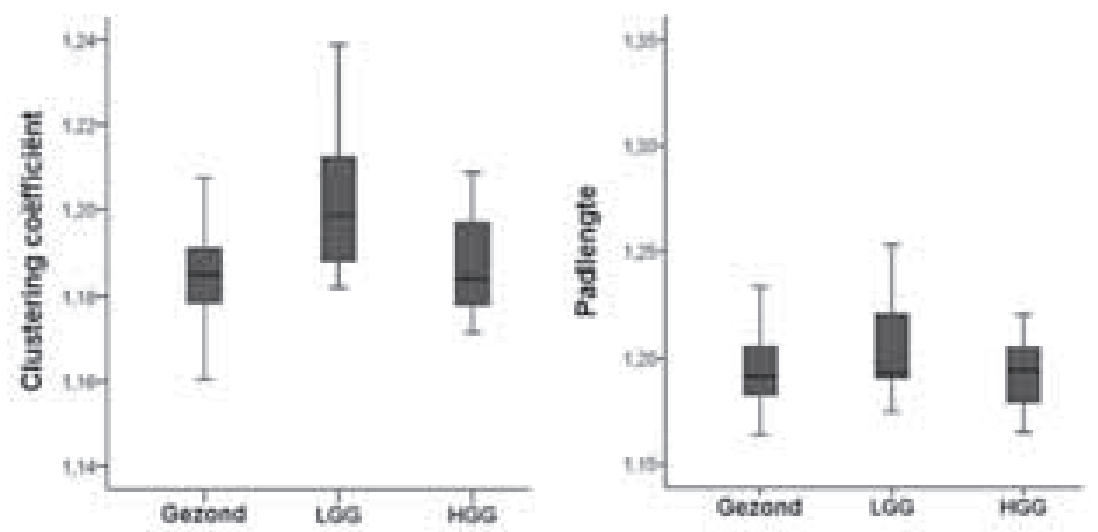

Figuur 3 Clustering coëfficiënt en padlengte in de thètaband bij gezonde proefpersonen, laaggradigglioompatiënten (LGG) en hooggradigglioompatiënten (HGG).

veel golven in de frequentieband die als eerste werd ontdekt: dealfaband, dieloopt tussen de 8 en $13 \mathrm{Hert}(\mathrm{Hz}$, d.w.z. aantal golven per seconde). Verschillendefrequentiebanden zijn ook geassocieerd met verschillende toestanden. Zo worden dehersengolven wanneer wegaan slapen steeds trager, tot ongeveer $1 \mathrm{~Hz}$. Tijdens zeer actief nadenken wordt het hersenritmejuist sneller, tot wel $80 \mathrm{~Hz}$. Bij hersentumorpatiënten is er vooral sterk toegenomen connectiviteit in de frequentietussen 4 en $8 \mathrm{~Hz}$, namelijk dethètaband. Dezefrequentieband is voornamelijk gerelateerd aan cognitievefuncties als werkgeheugen en aandacht.

Denetwerktopologievan hersentumorpatiënten is ook anders dan die van gezondemensen. In een popula tie patiënten met allerlei verschillende hersentumoren (ongeveer een derde laaggradig, tweederdehooggradig) is aangetoond dat zowel hun clustering als padlengtein allefrequentiebanden afneemt vergeleken met het gezonde small-world-netwerk (Bartolomei et al., 2006a). In een homogene groep van laaggradigglioompatiënten zijn echter andereresultaten gevonden. Deze patiënten vertonen als groep namelijk juist een toename in clustering coëfficiënt in dethètaband, terwijl deze- in overeenstemming met Bartolomei en collega's - afneemt in de bètaband ( 13 30 Hz; Bosma et al., 2009). Bij laaggradigglioompatiënten verschuift het hersennetwerk in dethètaband dus juist detegenovergestel dekant op.

Naast het feit dat door dezetwee onderzoeken duidelijk is geworden dat het hersenweb van hersentumorpatiënten anders is dan dat van gezondemensen, lijkt het erop dat het typehersentumor van invloed is op derichting van dezeveranderingen. In een zeer recentestudiezijn de verschillen in hersennetwerk in de thètaband tussen hooggradig-en laaggradigglioompatiënten en gezonde proefpersonen onderzocht (Van Dellen etal., 2011). Het blijkt dat de clusteringcoëfficiënt van laaggradigglioompatiënten sterk afwijkt van de gezonde proefpersonen, maar ook van de hooggradigglioompatiënten (zie figuur 3). Er zijn geen significanteverschillen in degemiddelde padlengte tussen de driegroepen.

Een mogelijkeverklaring voor dit verschil tussen laaggradigen en hooggradigen is, dateen laaggradig glioom langzamer groeit en meer infiltreert in het normale hersenweefsel dan een hooggradig glioom, dat heel snel groeit en eerder deal geheledruk in dehersenen verhoogt. Ook is er bij het laaggradig glioom meer tijd voor het hersennetwerk om te veranderen: tegen detijd dat detumor ontdekt wordt, zit dieer vaak al jarenlang.

\section{Acute netwerkveranderingen}

Dehierboven beschreven netwerkveranderingen bij hersentumorpatiënten zijn onderzocht in de maanden of jaren na het ontdekken van de tumor. Jekunt jeechter afvragen of netwerkveranderingen ook echt zo lang op zich laten wachten. Het onderzoeken van juist acute veranderingen in de hersenen is lastig omdat niemand die plotseling een herseninfarct krijgt op dat moment in een MRI - of MEGapparaat ligt.

Om toch een ideetekrijgen van dezesnelleaanpassingen in het hersennetwerk hebben wij een studie gedaan bij een bijzonderegroep patienten. Mensen met epilepsie diehed moeilijk te behandelen is met medicatie ondergaan namelijk soms een operatieom hen van hun aanvallen af tehelpen. Bij dezeoperatiewordt dat deel van dehersenen (meestal in detemporaal kwab), dat deepilepsie veroorzaakt, verwijderd. Om dit veilig tekunnen doen, wordt eerst getest of depatiënt in kwestiewel normaal kan blijven functioneren zonder dat stukjehersenen. Dit wordt gedaan door deverwijdering nate bootsen met behulp van verdoving. Alleen de hemisfeer waar het zieke gebied zit wordt gedurendeeen aantal minuten verdoofd. Dat geeft een neuropsycholoog de kans om het functioneren van het geheugen en detaal in degezonde hersenhelft tetesten. Dezeprocedure wordt de Wada-test genoemd, naar de ontdekker ervan (Wada, 1949).

Tijdens de Wadatest wordt ook het EEG opgenomen, wat ons dekans geeft netwerkanalyses uit te voeren in deze patiënten, dieeen acute 'beschadiging' van hun halvebrein 
ondervinden. De 30 seconden direct voor en direct na de verdoving zijn geanalyseerd. Deresultaten tonen aan dat defunctioneleconnectiviteit in zowel deverdoofdeals in decontralateralehemisfeer verandert. In deingespoten hemi sfeer treedt automatisch verhoging van de connectiviteit op. In dedeltaband $(1-4 \mathrm{~Hz})$ en thètaband neemt defunctioneleconnectiviteit in decontral aterale hemisfeer toe, terwijl dezejuist afneemt in debèta band (Douw et al., 2009). Wat betreft het gehelehersennetwerk: directna inspuiting wordt de clustering lager en depadlengtekorter (Douw et al., 2010a). Het is dus duidelijk dat ook binnen een minuut na beschadiging al functioneleveranderingen in het hersenweb optreden.

\section{Epilepsie en cognitie}

We weten nu dat hersentumorpatiënten niet alleen veranderdeconnectiviteit hebben op delocatievan de tumor, maar ook dat zewijdverspreide transformaties in hun gehele hersennetwerk vertonen. Zoals hiervoor beschreven, gaan hersentumoren vaak gepaard met zeer vervelende symptomen, zoals epileptischeaanvallen. Volgens sommigen is epilepsie bij uitstek een 'netwerkziekte', omdat een aanval eigenlijk een plotselinge hypersynchronisatie (d.w.z. verhoging van de connectiviteit) inhoudt. I nderdaad is aangetoond dat er tijdens een aanval substantiëleveranderingen in het hersennetwerk optreden.

Belangrijker voor dit artikel is echter of deafwijkendenetwerktopologiediehersentumorpatiënten op zichzelf al hebben, is gerelateerd aan deepilepsie. Dit blijkt het geval. In een groep hersentumorpatiënten die allemaal leden aan epileptischeaanvallen, bleek verhoogde functionele connectiviteit (gemeten met MEG) in dethètaband significant gecorreleerd tezijn meteen groter aantal aanvallen (Douw et al., 2010b). Ook een verhoogde padlengtewas geassocieerd met meer epilepsie. Dezecorrelatie van connectiviteiten netwerken in vooral dethètaband met kenmerken van de epilepsieis ook in anderestudies gebleken. Eerder zagen weal dat er vooral in denetwerktopologiein de thètaband verschillen zijn tussen laaggradig-en hooggradigglioompatiënten. Men zou kunnen speculeren dat dezeverschillen in netwerktopologie zich bij delaaggradigglioompatiënten uiten in een verhoogd risico op epileptischeaanvallen.

Derelatietussen netwerktopologieen cognitief functioneren bij gezonde proefpersonen is inmiddels behoorlijk overtuigend aangetoond, maar gaat dit verband nog steeds op bij hersentumorpatiënten? Bij laaggradigglioompatiënten is de eerder al beschreven verhoogdefunctionele connectiviteit in dethètaband inderdaad gecorreleerd met verslechterde cognitie (Bosma etal., 2008). Ook was bij dezepatiënten hun verhoogde clustering daadwerkelijk geassocierd met al gemene cognitieve problemen (Bosmaetal., 2009).

Zowel de epileptischeaanvallen als deglobaal verslechterde cognitie bij hersentumorpatiënten lijkt dus te maken tehebben met veranderingen in hun hersenweb. Toekomstig onderzoek zal echter moeten uitwijzen hoe deze driehoeksrelatieprecies in elkaar steekt.

\section{Hoop voor de toekomst}

Het toepassen van de netwerktheoriebij hersentumorpatiënten heeft behoorlijk wat inzicht in demeest voorkomende symptomen verschaft, maar is er ook nog een praktisch belang van denetwerktheorie bij deze patiënten? Recentestudies wijzen erop dat denetwerktheoriein de toekomst inderdaad de neurochirurgische behandeling van hersentumoren zal vergemakkelijken. Op dit moment wordt bij een operatiegeprobeerd de geheletumor te verwijderen. Dit is echter nog niet zo eenvoudig, aangezien zowel op preoperatievescans als met het bl oteoog het verschil tussen gezond en tumorweefsel maar moeilijk tezien is. Er is dus een risico dat een belangrijk stukjehersenen wordt verwij derd, waardoor de patiënt na afloop functieverlies kan ervaren. Door functioneleconnectiviteit te meten, kunnen deze problemen mogelijk vermeden worden. Gebieden die verlaagde connectiviteit vertonen, kunnen namelijk zonder postoperatieveuitval weggehaald worden (Guggisberg et al., 2008).

Ook belangrijk bij het opereren van hersentumorpatiënten is dat zena de operatiehopelijk geen epileptische aanvallen meer hebben. Het is echter ook nog steeds moeilijk om te bepalen waar de epilepsie precies vandaan komt. Dit kan namelijk nog behoorlijk ver van detumor zelf zijn. Het gebeurt dus nog behoorlijk vaak dat het focus (d.w.z. deoorsprong) van de epilepsie niet wordt weggehaald, waardoor patiënten epileptischeaanvallen blijven houden. Door met behulp van de netwerktheorievast testellen welke punten in het hersennetwerk het belangrijkst zijn voor het ontstaan en verspreiden van deaanvallen, kan de uitkomst van deoperatieverbeterd worden (Ortega et al., 2008a; 2008b).

Deze ontwikkelingen stimuleren verder onderzoek naar hersennetwerken bij hersentumorpatiënten. Zo kan iedere patiënt hopelijk een op maat gemaakteoperatie ondergaan waarbij enerzijds alle belangrijkefuncties gespaard worden, maar anderzijds de kans op epileptische aanvallen geminimaliseerd wordt. 


\section{Literatuur}

Bartolomei, F., Bosma, I., Klein, M., Baayen, J.C., Reijneveld, J.C., Postma, T.J., Heimans, J.J., Dijk, B.W. van, Munck, J.C. de, Jongh, A. de, Cover, K.S. \& Stam, C.J. (2006a). Disturbed functional connectivity in brain tumour patients: evaluation by graph analysis of synchronization matrices. Clinical N europhysiology, 117,9, 20392049.

Bartolomei, F., Bosma, I., Klein, M., Baayen, J.C., Reijneveld, J.C., Postma, T.J., Heimans, J.J., Dijk, B.W. van, Munck, J.C. de, Jongh, A. de, Cover, K.S. \& Stam, C.J. (2006b). How do brain tumors alter functional connectivity? A magnetoencephalography study. Annals of Neurology, 59,1, 128-38.

Bosma, I., Douw, L., Bartolomei, F., Heimans, J.J., Dijk, B.W. van, Postma, T.J., Stam, C.J., Reijneveld, J.C. \& Klein, M. (2008). Synchronized brain activity and neurocognitive function in patients with low-grade glioma: a magnetoencephalography study. N euroOncology, 10,5, 734-744.

Bosma, I., Reijneveld, J.C., Klein, M., Douw, L., Dijk, B.W. van, Heimans, J.J. \& Stam, C.J. (2009). Disturbed functional brain networks and neurocognitive function in low-grade glioma patients: a graph theoretical analysis of resting-state MEG. N onlinear Biomedical Physics, 3,1, 9.

Crofts, J.J., Higham, D.J., Bosnell, R., Jbabdi, S., Matthews, P.M., Behrens, T.E. \& Johansen-Berg, H. (2011). Network analysis detects changes in the contralesional hemisphere following stroke. Neuroimage, 54,1, 161-169.

Douw, L., Baayen, J.C., Klein, M., Velis, D., Alpherts, W.C., Bot, J., Heimans, J.J., Reijneveld, J. \& Stam, C.J. (2009). Functional connectivity in the brain before and during intra-arterial amobarbital injection (Wada test). N euroimage, 46,3, 584-588.

Douw, L., Dellen, E. van, Baayen, J.C., Klein, M., Velis, D.N., Alpherts, W.C., Heimans, J.J., Reijneveld, J.C. \& Stam, C.J. (2010a). The lesioned brain: still a small-world? Frontiersin H uman N euroscience, 4, 174 .

Douw, L., Dellen, E. van, Groot, M. de, Heimans, J.J., Klein, M., Stam, C.). \& Reijneveld, J.C. (2010b). Epilepsy is related to theta band brain connectivity and network topology in brain tumor patients. BioM ed Central Neuroscience, 11,1, 103.

Guggisberg, A.G., Honma, S.M., Findlay, A.M., Dalal, S.S., Kirsch, H.E., Berger, M.S. \& Nagarajan, S.S. (2008). Mapping functional connectivity in patients with brain lesions. A nnals of N eurology, 63, 193-203.

Klein, M., Taphoorn, M.J., Heimans, J J., Ploeg, H.M. van der, Vandertop, W.P., Smit, E.F., Leenstra, S., Tulleken, C.A., Boogerd, W., Belderbos, J.S., Cleijne, W. \& Aaronson, N.K. (2001). Neurobehavioral status and health-related quality of life in newly diagnosed high-grade glioma patients. J ournal of Clinical O ncology, 19,20, 4037-4047.

Milgram, S. (1967). The small world problem. Psychology today, 2, 60-67. Ortega, G.J., Menendez de la Prida, L., Sola, R.G. \& Pastor, J. (2008a). Synchronization clusters of interictal activity in the lateral temporal cortex of epileptic patients: intraoperative electrocorticographic analysis. Epilepsia, 49,2, 269-280.

Ortega, G.J., Sola, R.G. \& Pastor, J. (2008b). Complex network analysis of human ECoG data. N euroscience Letters, 447,2-3, 129-133.

Taphoorn, M.J. \& Klein, M. (2004). Cognitive deficits in adult patients with brain tumours. The Lancet N eurology, 3,3, 159-168.

Dellen, E. van, Douw, L., Hillebrand, A.J., Heimans, J.J., Ris-Hilgersom, I., Schoonheim, M.M., Baayen, J.C., Witt Hamer, P.C. de, Stam, C.J. \& Reijneveld, J.C. (2011). MEG functional connectivity and complex networks relate to clinical characteristics of lesional epilepsy patients. Aangeboden.

Wada, J. (1949). A new method for the determination of the side of cerebral speech dominance. A preliminary report on the intracarotid injection of sodium amytal in man (in Japanese). I gaku to seibutsugaki, 14, 221-222.

Wang, L., Yu, C., Chen, H., Qin, W., He, Y., Fan, F., Zhang, Y., Wang, M., Li, K., Zang, Y., Woodward, T.S. \& Zhu, C. (2010). Dynamic functional reorganization of the motor execution network after stroke. Brain, 133, (Pt 4), 1224-1238.

Watts, D.J. \& Strogatz, S.H. (1998). Collective dynamics of 'small-world' networks. Nature, 393,6684, 440-442. 